\title{
TRANSGENERIDADE E PREVIDÊNCIA SOCIAL: NOVOS HORIZONTES PARA SEGURADOS(AS) TRANS FRENTE ÀS MUDANÇAS JURÍDICAS NO CONTEXTO NACIONAL
}

\author{
Beatriz Lourenço Mendes* \\ José Ricardo Caetano Costa**
}

Resumo: O atual artigo discute os reflexos das mudanças jurídicas civis recentes para as pessoas trans no campo previdenciário, a partir da possibilidade de mudança do prenome e gênero diretamente no cartório civil, independente da realização de cirurgia de transgenitalização e de autorização judicial. Pelo método indutivo, analisam-se os discursos envolvidos na padronização dos corpos, a partir de Bento (2008). Após, verificam-se os principais marcos jurídicos relacionados ao reconhecimento das identidades de gênero no Brasil, com foco no julgamento da ADIN 4.275, pelo STF. Por último, examina-se os benefícios previdenciários sujeitos à análise de gênero, à luz das transformações civis ocorridas.

Palavras-chave: Transgeneridade; Previdência Social; Adin 4.275; Reconhecimento; Gênero.

\section{TRANSGENDER AND SOCIAL SECURITY: NEW HORIZONS FOR TRANSGENDER PEOPLE INSURED REGARDING LEGAL CHANGES ON THE NATIONAL SCENARIO}

\begin{abstract}
This study discusses the reflection of recent legal changes to transgender people on the social security field, based on the possibility of changing the first name and gender at a public civil registry, regardless of the sex reassignment surgery and judicial authorization. By inductive method, speeches involved on the standardization of bodies were analyzed based on Bento (2008). Thereupon, were verified the main judicial framework related to recognition of gender identity in Brazil, highlighting the ADIN 4.275 judgment by STF. Lastly, the benefits of the social security were examined and bounded to the gender analysis in view of nowadays changes.
\end{abstract}

Keywords: Transgender; Social Security; Adin 4.275; Recognition; Gender.

\footnotetext{
* Mestranda em Direito e Justiça Social pela Universidade Federal do Rio Grande (FURG) e Pesquisadora do Grupo Cidadania, Direitos e Justiça (CIDIJUS), e-mail: beatrizlmendes@outlook.com, endereço: Avenida Itália, $\mathrm{km} 8$, S/N, Casa do Estudante I, apto 202, FURG, Bairro Carreiros, Rio Grande - RS.

** Doutor em Serviço Social, Professor da Faculdade de Direito e ndo Programa de Pós-Graduação em Direito e Justiça Social na Universidade Federal do Rio Grande (FURG) e coordenador do grupo de Pesquisa e Extensão Cidadania, Direitos e Justiça (CIDIJUS), e-mail: jrcc.pel@ gmail.com, endereço: Rua Quinze de Novembro, 357 . Centro, Pelotas - RS.
}

Rev. de Direitos Sociais, Seguridade e Previdência Social | e-ISSN: 2525-9865 | Porto Alegre | v. 4 | n. 2 | p. 1 - 16 | Jul/Dez. 


\section{INTRODUÇÃO}

Em virtude das recentes mudanças de ordem jurídica no cenário brasileiro que impactam nas vidas das pessoas consideradas transgêneras ${ }^{1}$, este artigo se propõe a relacionar estas alterações civis com a Previdência Social, visto que a categoria gênero é parâmetro para a concessão de alguns benefícios previdenciários. Esta discussão será realizada levando em consideração a relevância dos discursos científico e jurídico na padronização dos corpos humanos e, consequentemente, na concessão ou negação de direitos à parcela da sociedade que mais sofre violações de direitos humanos: a comunidade trans.

Observa-se, no cenário brasileiro, a inexistência de legislação voltada ao reconhecimento da identidade de gênero. Esta lacuna legislativa, aparentemente, foi atenuada pelo novo entendimento do Supremo Tribunal Federal na Ação Direta de Inconstitucionalidade $\mathrm{n}^{\mathrm{o}} 4.275$, em que se previu a mudança de nome e $\operatorname{sexo}^{2}$ nos documentos de identidade das pessoas trans, de forma cartorária, bem como a prescindibilidade de autorização judicial para a efetuação de mudança de registro civil. No mesmo sentido, a Corregedoria Nacional de Justiça, em junho do corrente ano, normatizou a mudança de nome e gênero nos cartórios, em virtude da resistência de alguns destes em aderirem ao novo entendimento do STF.

Não obstante admirável o processo de reconhecimento das identidades de gênero de forma civil, faz-se necessária a integração dessas alterações para finalidades previdenciárias. Sendo assim, uma vez efetuada a alteração do registro civil da pessoa trans, ela deve passar a receber os benefícios conforme o gênero com o qual se identifica, independente do sexo morfológico com o qual tenha nascido, pois a autodeterminação de gênero corresponde a um direito constitucional de personalidade. Sem a compatibilidade das conquistas efetuadas na seara civil nas outras áreas do direito, não há o que se falar em avanços materiais para a comunidade trans.

\footnotetext{
${ }^{1}$ Utiliza-se o termo transgeneridade para abarcar a maior quantidade de identidades de gênero possíveis, incluindo transexuais e travestis, visto que o emprego somente do termo "transexual" pode vir a excluir pessoas que não passaram pela cirurgia de transgenitalização. Conforme Jesus (2010, p. 17), ao se utilizar a expressão "transgênero" coloca-se a questão da identidade de gênero como primordial para a garantia de direitos. Ainda, para conferir maior fluidez ao trabalho, os(as) autores(as) optaram pela utilização da abreviação "trans" para se referir às pessoas transgêneras.

${ }^{2}$ Utiliza-se a expressão "sexo" por ser o termo constante nos documentos de identidade, embora os(as) autores(as) concordem que "gênero" seria o vocábulo mais adequado, tendo em vista que as pessoas trans são caracterizadas por não se identificarem com o próprio sexo morfológico e, por este motivo, performam o gênero contrário.
} 
Nesta toada, este trabalho tem como propósito mapear os possíveis avanços operados na esfera jurídica brasileira, recentemente, para a comunidade transgênera, a partir do método indutivo. Esta pesquisa torna-se imprescindível na medida em que o Brasil é considerado um dos países onde mais se mata transexuais e travestis no mundo ${ }^{3}$, sendo incumbência dos(as) juristas e pesquisadores(as) a luta pelo resguardo dos direitos fundamentais desta parcela da população.

Para se atingir o propósito esperado, as principais bases teóricas para articular o debate proposto será a partir da concepção de gênero para Butler (2003), bem como a discussão de Bento (2008) sobre os possíveis eixos segundo os quais as pessoas trans são tratadas pelo Estado, ou seja, por vieses de reconhecimento ou autorização. Ademais, também se empregam jurisprudências e artigos científicos a respeito da temática em questão.

Salienta-se, ainda, que o presente artigo não tem o condão de esgotar o debate relacionado à categoria de gênero, tampouco a relação deste com a área previdenciária, limitando-se a abordar pontualmente as questões supracitadas. Além disso, por ser uma temática deveras atual, que somente neste ano ganhou repercussão jurídica nacional, ainda não se sabem os desdobramentos posteriores acerca dos reflexos da alteração do registro civil das pessoas trans na seara do direito previdenciário, podendo vir a ser regulamentada a posteriori.

\section{OS DISCURSOS HEGEMÔNICOS ENVOLVIDOS NA PADRONIZAÇÃO DOS CORPOS}

Antes de se adentrar sobre a questão dos discursos de poder envolvidos no controle dos corpos humanos, faz-se necessário introduzir o conceito de gênero que será utilizado no presente artigo. Emprega-se, no decorrer do trabalho, o termo gênero como uma construção cultural que não se relaciona com a questão biológica do sexo, ou seja, o fato de uma pessoa nascer com o órgão reprodutor feminino não a torna, necessariamente, mulher.

Assim sendo, ao se naturalizar o discurso de gênero, também se ocultam os mecanismos de poder envolvidos na manutenção do status quo. A partir disso, constata-se a

\footnotetext{
3 Conforme mapeamento realizado em 2016 pela ONG Transgender Europe, através da lista "TransMurderMonitoring" (TMM), em português, Monitoramento de Assassinatos de Trans e de pessoas com gênero diverso, o Brasil liderou as pesquisas, entre 33 países, sendo responsável por 123 mortes nos últimos 12 meses que antecederam as pesquisas. Fonte: https://transrespect.org/en/map/trans-murder-monitoring/
} 
apropriação das normas de gênero pelos discursos hegemônicos, aprisionando os corpos dentro da lógica cisgênero e heteronormativa, segundo a qual todas as pessoas devem exprimir o próprio gênero conforme o sexo que nasceram, além de se impor a heterossexualidade como única forma viável de relacionamento, desde os primórdios da formação escolar infantil.

Butler (2003) aduz que as estruturas de poder da sociedade são responsáveis por cristalizar as identidades de gênero, gerando binarismos como homem/mulher, heterossexual/homossexual, dentre outros. Para a autora, gênero é uma categoria produzida e não um fato natural. Em outras palavras, a autora defende que os seres humanos são moldados, culturalmente, a se portarem conforme as normas de gênero impostas de forma hegemônica.

a ideia de que o gênero é construído sugere um certo determinismo de significados do gênero, inscritos em corpos anatomicamente diferenciados, sendo esses corpos compreendidos como recipientes passivos de uma lei cultural inexorável. Quando a 'cultura' relevante que 'constrói' o gênero é compreendida nos termos dessa lei ou conjunto de leis, tem-se a impressão de que o gênero é tão determinado e tão fixo quanto na formulação de que a biologia é o destino. Nesse caso, não a biologia, mas a cultura se torna o destino. (BUTLER, 2003, p.26)

Observa-se, porém, que a transgeneridade suplanta as normas de gênero impostas socialmente, ao dissociar o sexo morfológico exteriorizado no momento do nascimento, da performance social que a pessoa transgênera exerce. Isto é, a pessoa trans se comporta de forma oposta ao esperado para um homem, no caso de ter nascido com o órgão reprodutor masculino ou uma mulher, acaso tenha nascido com órgão reprodutor feminino.

Neste aspecto, surgem o discurso jurídico e o discurso científico como principais responsáveis pelo exercício do controle dos corpos. O primeiro é revelado pelas legislações, que possuem o condão de resguardar ou não os direitos de certos indivíduos e, em caso negativo, relegá-los à marginalidade. $\mathrm{O}$ discurso científico, por sua vez, é responsável pela rotulação entre o que é considerado "normal" e o que é "anormal".

O vínculo entre estas formas discursivas e a consequente imposição que este padrão exerce é crucial para a comunidade trans, visto que inexiste lei, no Brasil, que reconheça a identidade de gênero adotada por pessoas trans, e, ao mesmo tempo, a transgeneridade foi considerada patológica até meados de junho vigente ano, vindo a ser retirada do catálogo de doenças mentais pela Organização Mundial da Saúde. No mesmo sentido, assevera Bento:

A transexualidade e outras experiências de trânsito entre os gêneros demonstram que não somos predestinados a cumprir os desejos de nossas 
estruturas corpóreas. O sistema não consegue a unidade desejada. Há corpos que escapam ao processo de produção dos gêneros inteligíveis, e ao fazê-lo, se põem em risco porque desobedeceram às normas de gênero: ao mesmo tempo, revelam as possibilidades de transformação dessas mesmas normas. (BENTO, 2008, p. 38)

Depreende-se, assim, que da mesma forma com que as verdades construídas socialmente para os gêneros foram estabelecidas e naturalizadas, é possível que os gêneros considerados subversivos disputem a produção de discursos contra hegemônicos que escapem das normas de gênero binárias atualmente difundidas. Em verdade, é o que se espera que ocorra com as recentes mudanças a nível nacional e internacional nos últimos tempos, efetivadas por inúmeras instituições, conforme se verá adiante.

Bento (2008) ainda discorre que o Estado, através dos discursos de poder, pode encarar a transgeneridade por duas óticas, ou seja, por eixos de reconhecimento ou eixos de autorização. Na concepção da autora, vinculada à época em que a obra foi escrita, o Brasil, por meio, tanto do discurso jurídico, quanto o discurso científico, adotava uma concepção autorizativa. Esta última condiciona o reconhecimento das identidades trans, a partir da permissão de um sujeito elegido como detentor do conhecimento, sendo representado pelo juiz, na seara jurídica, e pelo médico na esfera da saúde.

De fato, antes das alterações jurídicas sucedidas neste ano, que serão melhor analisadas no próximo tópico, exigiam-se incansáveis laudos médicos e acompanhamento psicológico durante dois anos para que o médico atestasse a transgeneridade de um indivíduo. Ainda assim, não obstante a burocracia médica envolvida para autorizar a cirurgia de transgenitalização, o indivíduo trans que desejasse alterar os assentos no registro de nascimento, quanto ao nome e ao gênero, também deveria encarar um processo judicial, correndo o risco de ter sua pretensão de exprimir os próprios direitos de personalidade negada.

Os órgãos e instituições de renome internacional aparentam estar se adequando à pluralidade de demandas sociais surgidas nos últimos anos, em respeito aos direitos humanos e, mais especificamente no caso brasileiro, ao princípio da dignidade da pessoa humana. Ao se retomar a discussão de Bento (2008) sobre como são assimiladas as identidades de gênero em cada sociedade, vislumbra-se uma evolução da lógica de autorização para a lógica de reconhecimento no campo médico-científico.

Em 18 de junho de 2018, a coordenadora do Departamento de Saúde Reprodutiva e Pesquisa da Organização Mundial da Saúde (ONU), Dra. Lale Say declarou que a ONU 
desclassificará a transgeneridade da lista de doenças mentais. Este avanço demonstra um marco importantíssimo para a era de reconhecimento e celebração da diversidade de gênero. Senão vejamos:

\begin{abstract}
Gender incongruence, meanwhile, has also been moved out of mental disorders in the ICD, into sexual health conditions. The rationale being that while evidence is now clear that it is not a mental disorder, and indeed classifying it in this can cause enormous stigma for people who are transgender, there remain significant health care needs that can best be met if the condition is coded under the ICD" (WHO, WHO releases new International Classification of Diseases ICD-11, june, 2018) ${ }^{4}$
\end{abstract}

A retirada gradativa do transexualismo ${ }^{5}$ do rol de doenças mentais pela ONU, passando a considerá-lo uma condição de saúde sexual, pode ser considerado um progresso inquestionável para a comunidade LGBTTQI ${ }^{6}$. Este novo paradigma assinala uma guinada da comunidade médico-científica internacional ao eixo de reconhecimento da diversidade de gênero. Resta realizar uma breve análise acerca dos processos de reconhecimento no cenário jurídico brasileiro, a partir do entendimento do STF, na ADI 4.274. É o que se dedica o próximo tópico deste trabalho.

\title{
3. ASPECTOS JURÍDICOS NO RECONHECIMENTO DAS IDENTIDADES DE GÊNERO: RANÇOS E AVANÇOS NO CENÁRIO BRASILEIRO
}

O presente tópico se concentra em verificar as mudanças paradigmáticas operadas no aparato jurídico brasileiro, com foco na questão da identidade de gênero, tendo como marco o julgamento pelo Supremo Tribunal Federal da ADIN 4.245. Propõe-se, também a verificar se o Estado, por meio do Poder Judiciário, compreende a transgeneridade a partir de eixos de autorização ou de reconhecimento, conforme proposto por Bento (2008), da mesma forma como se analisou o discurso médico-científico anteriormente. Além disso, conferir-se-á destaque para

\footnotetext{
${ }^{4}$ Tradução livre dos(as) autores(as): A incongruência de gênero, enquanto isso, também foi removida da seção de desordens mentais do CID, para condições de saúde sexual. A lógica é que a evidência agora é clara que isso não é uma desordem mental, e de fato, classificando-a desta maneira, pode causar estigmas enormes para pessoas que são transgêneras, todavia, existem necessidades remanescentes de saúde significantes que podem ser melhor atingidas caso a condição seja codificada dentro do CID.

${ }^{5}$ Aqui se fala em transexualismo pois se refere à categoria médica na qual a condição da transgeneridade foi inserida, sob o CID F64.0. Isto é, "transexualismo" é o termo médico que caracteriza a transgeneridade como patologia, embora os(as) autores(as) do trabalho discordem que se trata de uma doença mental e a considerem como identidade de gênero.

${ }^{6}$ Sigla para determinar o grupo de diversidade de gênero e sexualidade formado por Lésbicas, Gays, Bissexuais, Transexuais, Travestis, Queers e Intersexuais.
} 
os possíveis avanços e retrocessos na legislação e jurisdição brasileiras, tendo como pano de fundo o contexto latino-americano.

Primeiramente, cumpre realizar um resgate sobre a Lei de Registros Públicos (Lei 6.015/73). Esta prevê no art. 58, caput, que o prenome é definitivo, admitindo-se, todavia, sua substituição por apelidos notórios. Por este motivo, toda pessoa trans que desejasse proceder à alteração do próprio registro, até o início deste ano, deveria ingressar com um processo judicial, pois conforme o parágrafo único do mesmo artigo, a substituição do prenome é condicionada à sentença judicial e à oitiva do Ministério Público.

No entanto, a partir da ADIN 4.275, julgada em março de 2018, o Supremo Tribunal Federal confere procedência à ação para dar Interpretação Conforme à Constituição e ao Pacto de São José da Costa Rica ao art. 58, da Lei de Registros Públicos. Desta feita, torna-se possível realizar a alteração de prenome e de gênero das pessoas trans independentemente da cirurgia de transgenitalização e de forma direta no cartório de registro civil, ou seja, dispensa-se a sentença judicial. Nesse sentido, insta mencionar parte do voto do Ministro Relator Marco Aurélio na referida ADIN:

(...) figura-me inviável e completamente atentatório aos princípios da dignidade da pessoa humana, da integridade física e da autonomia da vontade, condicionar o exercício do legítimo direito à identidade à realização de um procedimento cirúrgico ou de qualquer outro meio de se atestar a identidade de uma pessoa. Evidencia-se, assim, com olhar solidário e empático sobre o outro, que inadmitir a alteração do gênero no assento de registro civil é atitude absolutamente violadora de sua dignidade e de sua liberdade de ser, na medida em que não reconhece sua identidade sexual, negando-lhe o pleno exercício de sua afirmação pública. (ADI 4275 / DF)

O trecho supracitado pertencente ao voto do Ministro Marco Aurélio sustenta a responsabilidade do Estado em conferir tratamento igual aos(às) cidadãos(ãs), de forma que que todos(as) possam viver com dignidade e respeito. Este posicionamento coaduna com a perspectiva de que a comunidade jurídica tende a adotar uma racionalidade de reconhecimento das identidades de gênero, em oposição à lógica autorizativa, conforme previu Bento (2008).

Como outrora mencionado, verifica-se que o entendimento do STF se trata de alteração deveras recente, de modo que já é possível observar algumas repercussões relativas a esta mudança de paradigma jurídico. Alguns cartórios se negaram a proceder a alteração do prenome e do gênero de pessoas trans de forma direta, motivo que levou alguns estados da federação a 
editarem provimentos para se fazer cumprir a decisão prolatada na referida ADIN, como o estado de Goiás e do Rio Grande do Sul.

Finalmente, em 28 de junho de 2018, a Corregedoria Nacional de Justiça editou o provimento $n^{\circ} 73$, considerando inúmeros aspectos relevantes sobre a identidade de gênero decididos nos últimos meses, como a decisão da Organização Mundial da Saúde em excluir a transexualidade do capítulo de doenças mentais do CID e a decisão do STF acima relatada. Este provimento vincula o Registro Civil de Pessoas Naturais (RCPN) a alterar o prenome e gênero nos assentos de nascimento e casamento de pessoas transgêneras, independentemente de cirurgia de transgenitalização e de autorização judicial.

Importante destacar o art. $4^{\circ}$ do provimento exposto: "O procedimento será realizado com base na autonomia da pessoa requerente, que deverá declarar, perante o registrador do RCPN, a vontade de proceder à adequação da identidade mediante a averbação do prenome, do gênero ou de ambos". O aduzido trecho demonstra o princípio da autonomia da pessoa requerente, além de dispor no art. $7^{\circ}$ que a apresentação de laudos médicos para atestar a condição de transexualidade/travestilidade é opcional, situação completamente diversa da experimentada por pessoas trans no Brasil que pretendiam alterar o nome e/ou o gênero antes do entendimento do STF na ADIN 4.275.

O visível progresso do pensamento jurídico no Brasil, como a maior parte dos avanços sociais regulamentados, tem os primórdios nas lutas da comunidade LGBTTQI em terem os próprios direitos reconhecidos, como o casamento homossexual, o direito à adoção, dentre outros direitos já exercidos por cidadãos(ãs) que correspondem ao padrão de gênero e sexualidade considerados "normais" pelos discursos de poder hegemônicos, como visto no primeiro tópico deste artigo.

Além disso, a experiência latino-americana em editar leis de reconhecimento de identidade de gênero também é responsável pelo êxito brasileiro em pacificar a questão jurisprudencialmente. Em uma perspectiva de direito comparado, cita-se o Uruguai (2009), a Argentina (2012) e a Bolívia (2016) como pioneiros em editarem Leis de Identidade de Gênero. Com efeito, as iniciativas dos vizinhos Uruguai e Argentina impulsionaram a tentativa de aprovação do Projeto de Lei brasileiro 5.002/2013 para dar fim à omissão legislativa no que tange ao reconhecimento da identidade de gênero pelo Estado Brasileiro. 
De iniciativa do deputado Jean Wyllis (PSOL) e Érika Kokay (PT), o referido projeto de lei, também conhecido como Projeto de Lei João Nery, em homenagem ao primeiro trans homem a realizar a cirurgia de transgenitalização no Brasil, se espelhava na Lei de Identidade de Gênero Argentina e buscava consagrar o direito das pessoas trans em serem tratadas conforme a própria identidade de gênero, a partir dos instrumentos que atestem a própria identidade pessoal, como imagem e documentos. A fim de dialogar com o Provimento $\mathrm{n}^{\mathrm{o}} 73$ do $\mathrm{CNJ}$, cita-se o art. $4^{\circ}$ deste projeto de lei:

Artigo $4^{\circ}$ - Toda pessoa que solicitar a retificação registral de sexo e a mudança do prenome e da imagem, em virtude da presente lei, deverá observar os seguintes requisitos: I - ser maior de dezoito (18) anos; II - apresentar ao cartório que corresponda uma solicitação escrita, na qual deverá manifestar que, de acordo com a presente lei, requer a retificação registral da certidão de nascimento e a emissão de uma nova carteira de identidade, conservando o número original; III - expressar o/s novo/s prenome/s escolhido/s para que sejam inscritos.

Parágrafo único: Em nenhum caso serão requisitos para alteração do prenome: I - intervenção cirúrgica de transexualização total ou parcial; II - terapias hormonais; III - qualquer outro tipo de tratamento ou diagnóstico psicológico ou médico; IV - autorização judicial.

Observa-se que o referido artigo do projeto de lei prevê a dispensa da cirurgia de transgenitalização, no parágrafo único, inciso I, bem como a prescindibilidade de autorização judicial para a retificação registral, no inciso IV. Além disso, o art. 12 do Projeto de Lei João Nery ainda apresenta uma proposta de modificação para art. 58, da Lei de Registros Públicos, adicionado a redação seguinte "O prenome será definitivo, exceto nos casos de discordância com a identidade de gênero auto-percebida, para as quais se aplicará a lei de identidade de gênero".

Realiza-se este quadro comparativo com a finalidade de demonstrar que o Projeto de Lei $\mathrm{n}^{\circ} 5.002 / 2013$, há cerca de cinco anos atrás, pretendia regulamentar a condição da transgeneridade de forma a acabar com a omissão legislativa no tocante à identidade de gênero. Todavia, o projeto desde 2014 aguarda parecer do relator na Comissão de Direitos Humanos e Minorias. A consequência desta mora legislativa é, certamente, inescusável para a comunidade trans, que poderia já exercer livremente o direito de alteração de registro notorial quanto ao nome e ao gênero desde 2013, caso a lei tivesse sido promulgada.

Sem embargo, como decorrência desta delonga, tornou-se necessário o julgamento de diversas ações judiciais até que o STF pacificasse a questão, a edição de provimentos estaduais 
para incorporar a decisão do Supremo, bem como a edição de Provimento pela Corregedoria Nacional de Justiça, tudo isso a fim de uniformizar a situação referente à alteração de registro de pessoas trans.

Não obstante estas decisões e documentos editados com a finalidade de regulamentar a questão, verifica-se que todos estes diplomas se concentram em dispor, mormente, sobre a questão de alteração do registro civil. Desta forma, atesta-se que a aprovação da Lei de Identidade de Gênero regulamentaria de forma mais articulada o reconhecimento do livre exercício do direito de personalidade da pessoa trans, por prever outras questões paralelas à alteração do registro, como a proibição de norma que limite, restrinja, exclua ou suprima o exercício do direito à identidade de gênero, conforme dispõe o artigo 11, do projeto de lei João Nery.

Em breve síntese, pôde se depreender que o atual discurso jurídico brasileiro demonstrou um comprometimento com os diplomas internacionais de direitos humanos, ao adotar uma postura de reconhecimento das identidades de gênero. Entretanto, identifica-se que o ativismo judicial poderia ter sido evitado no caso em tela, a partir da aprovação do Projeto de Lei 5.002/2013, que regulamentaria de forma mais abrangente a situação e conferiria maior segurança jurídica aos indivíduos que dela dependem para concretizar os próprios direitos, tendo em vista que a ADI 4.275 se limitou a tratar de questões civis, de modo que, nas outras esferas, os direitos da comunidade trans permanecem despercebidos. Além disso, resta examinar como esta conquista obtida na seara do Direito Civil reflete nas políticas do Regime Geral de Previdência Social, como se verá a seguir.

\section{A ADEQUAÇÃo NECESSÁRIA DAS CONQUISTAS DE ORDEM CIVIL NO ÂMBITO PREVIDENCIÁRIO}

O presente tópico busca desenvolver uma análise sobre as consequências do reconhecimento da condição transgênera na Previdência Social, em virtude de a categoria gênero ser um aspecto relevante na concessão de alguns benefícios, como a aposentadoria por idade e por tempo de contribuição, principalmente. Em outras palavras, será realizada uma abordagem sobre como as transformações políticas e culturais modernas refletem na garantia dos direitos sociais, os quais têm por função precípua assegurar o mínimo de qualidade de vida e dignidade aos(às) cidadãos(ãs).

Rev. de Direitos Sociais, Seguridade e Previdência Social | e-ISSN: 2525-9865 | Porto Alegre | v. 4 | n. 2 | p. 1 - 16 | Jul/Dez. 
A Constituição da República Federativa Brasileira de 1988 é, sem dúvida, fruto de diversas lutas de movimentos sociais empreendidas na década de 1980, principalmente as garantias estabelecidas às mulheres, que reivindicaram pela Carta das Mulheres Brasileiras ao Constituinte, transformações políticas e sociais, a fim de dirimir a situação de opressão e subordinação histórica das mulheres.

Entretanto, o contexto da década de 1980 em relação à conjuntura atual, já está permeado por novos conflitos e mudanças que necessitam ser consagradas pelo legislador. Tem-se que as conquistas advindas da Constituição Federal e dos movimentos sociais, embora louváveis, atingiram unicamente as mulheres cisgêneras, isto é, aquelas que biologicamente nasceram com órgãos reprodutores considerados femininos. Assim, as mulheres transgêneras permaneceram até então sem as garantias constitucionais feministas conferidas à mulher cis, em virtude das omissões legislativas já mencionadas amplamente no decorrer deste trabalho.

Atualmente, com a garantia cristalizada na esfera do Direito Civil, a fim de possibilitar a alteração do registro das pessoas transgêneras, no que toca ao prenome e ao gênero, é preciso realizar uma hermenêutica constitucional coerente com um dos objetivos materiais da Constituição Federal: promover o bem de todos(as), sem preconceitos de origem, raça, sexo, cor, idade e quaisquer outras formas de discriminação. Para tanto, mesmo com a omissão legislativa sobre o assunto, é possível se extrair do princípio da dignidade humana que o legislador intenciona conferir tratamento igualitário a pessoas cisgêneras e transgêneras. Sobre o assunto, assevera Souza:

É notória a constatação de que as mulheres transexuais não recebem o mesmo tratamento e as mesmas oportunidades oferecidas às mulheres não transexuais, denominadas de cisgêneras. Diante das mulheres cisgêneras, popularmente denominadas como mulheres "de verdade", as mulheres transexuais se veem vítimas do machismo e sexismo de base legal e biologizante que negam a estas a possibilidade de vivenciarem sua feminilidade em toda a sua amplitude. Em geral, quando as políticas sociais contemplam iniciativas que põem em foco a categoria gênero, visualizamos que estas centram somente na "mulher biológica", geralmente excluindo na prática grupos altamente estigmatizados e oprimidos, como as mulheres transexuais. (SOUZA, 2015, p. 6)

Como outrora mencionado, existem benefícios de ordem previdenciária que estão sujeitos à variável de gênero, como é o caso da aposentadoria por idade e da aposentadoria por contribuição. No que tange à aposentadoria pode idade, esta é concedida no patamar de 60 (sessenta) anos para as seguradas mulheres e 65 (sessenta e cinco) anos para segurados homens, sendo reduzidas em cinco anos para trabalhadores(as) rurais. A aposentadoria por tempo de 
contribuição, por sua vez, é concedida a partir de 35 (trinta e cinco anos) de contribuição para segurados homens, ao passo que para as mulheres se alcança ao obter 30 (trinta) anos de contribuição.

Nesse sentido, a partir da retificação do prenome e gênero do registro civil, também se faz necessária a alteração destes elementos nos assentamentos do Instituto Nacional de Seguridade Social (INSS), a fim de que cada segurado(a) passe a receber os benefícios conforme o gênero com o qual se identifica, independente do sexo morfológico com o qual tenha nascido.

Cruz (2014) ainda observa que o segurado transgênero homem, em tese, restaria prejudicado pelo labor adicional de cinco anos para obter a aposentadoria, todavia este interim adicional de trabalho e contribuição evidenciaria que este é reconhecido perante a sociedade e pelo ordenamento jurídico como homem, sendo um ônus suportado, em virtude do reconhecimento da identidade de gênero. A recíproca também é considerada verdadeira, pois as mulheres transgêneras, apesar de obterem a aposentadoria com antecedência de cinco anos em relação aos homens, sofrem com os percalços do mundo do trabalho, como salários menores e com o trabalho doméstico não remunerado.

Freitas e Vita (2017) reconhecem a necessidade de uma ponderação de valores e princípios constitucionais fundamentais para a legitimação do direito à aposentadoria por segurados(as) trans, enquanto não se vislumbra legislação própria para normatizar a questão. Sendo assim, consideram o critério proporcional misto como o mais adequado para o tratamento previdenciário das pessoas transgêneras.

Este parâmetro consiste no cálculo da contribuição e idade do segurado proporcionalmente até o instante em que se opera a mudança constitutiva do gênero no registro civil. A partir deste momento, o período contributivo remanescente obedeceria ao novo gênero adotado, passando a operar para todos os efeitos de direito. Para melhor ilustrar a situação, vejamos:

um homem transexual (biologicamente pertencente ao sexo feminino), que teve alterado o seu Assento constante do RCPN em decorrência de mudança de nome e sexo, que já havia contribuído (enquanto ainda do sexo feminino), por 20 (vinte) anos (equivalente a $2 / 3$ ou $66,6666 \%$ do período aquisitivo da aposentadoria por tempo de contribuição para mulheres), a partir desse critério, necessitaria ainda contribuir pelo período equivalente a cerca de 11 anos e 241 (duzentos e quarenta e um) dias (cerca de 8 meses), equivalente a 
$1 / 3$ ou $33,3333 \%$ do período aquisitivo da aposentadoria por tempo de contribuição para homens, para aposentar-se na forma do Art. 201, § $7^{\circ}$, I, da $\mathrm{CF}$, ao totalizar 31 anos e 8 meses de contribuição. No caso de aposentadoria por idade, levar-se-ia em consideração - proporcionalmente - a idade que possuía ao tempo do efeito constitutivo da alteração do sexo perante o RCPN. (FREITAS, VITA, 2017, p. 313)

A proposta apresentada pelos autores aparenta ser a mais adequada para ser adotada pelo INSS, a fim de conceder a proteção constitucional devida à parcela transgênera da população brasileira, que já enfrenta diversos desafios relativos ao mercado de trabalho e à vulnerabilidade social que está inserida, em razão da própria identidade de gênero. Assim, o critério proporcional misto aparece como uma solução equilibrada e não discriminatória, que não afeta o equilíbrio financeiro da Previdência Social e ainda respeita a dignidade das pessoas transgêneras.

Em suma, constata-se que a possibilidade de alteração do registro civil quanto ao nome e ao gênero expressa somente uma, das muitas conquistas ainda necessárias, para que a comunidade transgênera brasileira possa viver dignamente. Como discorrido neste capítulo, é imprescindível que o INSS adapte os assentos internos dos(as) segurados(as), a partir da alteração registral quanto ao nome e gênero realizados junto ao Registro Civil de Pessoas Naturais (RCPN).

Para além disso, em nome dos princípios constitucionais de igualdade, personalidade e de dignidade humana, é imperioso que cada segurado(a) trans receba os benefícios atinentes ao próprio gênero adotado, isto é, de acordo com a performance social de cada um(a) perante a sociedade. Propõe-se, como método adequado para cálculo do período contributivo destes(as) segurados(as), e consequente aposentadoria deles(as), o critério proporcional misto, conforme narrado, dada a inexistência de legislação que aborde a questão em tela.

\section{CONSIDERAÇÕES FINAIS}

Diante das discussões apresentadas neste artigo, identificaram-se algumas das dificuldades enfrentadas pela comunidade trans no Brasil, a começar pela naturalização dos discursos de poder que tratam gênero como uma característica inata ao sexo do ser humano, de modo a segregar indivíduos que não obedecem a estas normas sociais. 
Neste contexto, aludiu-se ao discurso médico-científico e ao discurso jurídico como os maiores responsáveis por solapar os direitos da comunidade transgênera. A ausência de legislação expressa que reconheça a identidade de gênero, aliada à histórica patologização da condição de transgeneridade relega à pessoa trans no Brasil a qualidade de homo sacer, aludindo-se à Agamben (2007), isto é, sujeito expulso do grupo social, excluído de todos os direitos civis e cuja existência não importa ao Estado.

No que tange ao tratamento conferido pelo Estado aos indivíduos trans, foi possível observar uma mudança paradigmática no cenário brasileiro recentemente. A partir da discussão proposta por Bento (2008), atesta-se que o Brasil seguia uma corrente autorizativa, isto é, condicionava o reconhecimento de direitos das pessoas transgêneras a uma autoridade.

Todavia, as recentes mudanças ocasionadas a partir do julgamento da ADIN 4.275 pelo STF, demonstra uma guinada do discurso jurídico ao eixo de reconhecimento das identidades de gênero. No mesmo sentido, o discurso médico-científico aponta o mesmo caminho, com a recente retirada do transexualismo do rol de doenças mentais da Classificação Internacional de Doenças e Problemas Relacionados à Saúde (CID 10) pela ONU.

Ademais, verifica-se ainda que não obstante aclamáveis as conquistas jurídicas no cenário brasileiro, a falta de lei específica que disponha sobre o reconhecimento das identidades de gênero ainda gera a persistência de diversos entraves para a consecução dos direitos sociais das pessoas trans. Por este motivo, defende-se a importância da aprovação do Projeto de Lei 5.002/2013, apesar de pacíficas a questão de alteração do registro civil da pessoa trans, por se compreender que o diploma legal confere mais segurança jurídica à comunidade transgênera, pois abrange de maneira mais holística a expressão da identidade de gênero.

Por fim, reitera-se que as garantias conquistadas na seara cível devem repercutir nos outros âmbitos do direito, principalmente na área previdenciária, responsável pela proteção dos cidadãos quando da perda da capacidade laboral. Uma vez concedida a possibilidade de alteração de gênero de um(a) segurado(a) filiado(a) ao Regime Geral de Previdência Social (RGPS), é preciso que todo o aparato estatal esteja preparado para proceder, também, as alterações necessárias nos registros internos do INSS.

Por conseguinte, também é medida de justiça social que cada segurado(a) receba os benefícios de aposentadoria por idade e aposentadoria por contribuição conforme o gênero adotado e retificado em cartório. Destaca-se que tal medida não reflete em prejuízos para o 
sustento da Previdência, haja vista a possibilidade de utilização do critério proporcional misto para o cômputo da aposentadoria; e do ponto de vista social cumpre com os preceitos constitucionais em garantir que toda pessoa tenha uma vida digna, bem como a honra e a imagem preservadas.

\section{REFERÊNCIAS BIBLIOGRÁFICAS}

AGAMBEN, Giorgio, Homo sacer. O poder soberano e a vida nua. Trad.: Henrique Burigo. Belo Horizonte: UFMG, 2007.

ARGENTINA. Ley n. 26.743, de 9 de maio de 2012. Establéceseelderecho a La identidad de género de las personas. Boletín Oficial de la República Argentina, Buenos Aires, 23 maio 2012. Disponível em: <http://www.buenosaires.gob.ar/derechoshumanos/convivencia-en-ladiversidad/normativas/ley-26743-de-identidad-de-genero> Acesso em 23 de junho de 2018.

BENTO, Berenice. O que é transexualidade. Coleção Primeiros Passos; 328p., Editora Brasiliense. São Paulo, 2008

BRASIL. "Projeto de Lei n. 5.002/2013." Dispõe sobre o direito à identidade de gênero e altera o artigo 58. Autores: Jean Wyllys - PSOL/RJ, Erika Kokay - PT/DF. Apresentação: 20/02/2013. Disponível

em:

http://www.camara.gov.br/proposicoesWeb/fichadetramitacao?idProposicao=565315. Acesso em $1^{\circ}$ de agosto de 2018 .

BRASIL. Conselho Nacional de Justiça. Provimento $n^{\circ} 73$, de 28/06/2018, Dispõe sobre a averbação da alteração do prenome e do gênero nos assentos de nascimento e casamento de pessoa transgênero no Registro Civil das Pessoas Naturais (RCPN). Disponível em: http://www.cnj.jus.br/files/conteudo/arquivo/2018/06/434a36c27d599882610e933b8505d0f0. pdf. Acesso em 01 de agosto de 2018.

BRASIL. Constituição da República Federativa do Brasil: texto constitucional promulgado em 5 de outubro de 1988, com as alterações adotadas pelas Emendas Constitucionais nº $1 / 92 \mathrm{e}$ 56/2007. Brasília - DF: Senado Federal, 2008.

BRASIL. Supremo Tribunal Federal. Notícias STF, sexta feira, 02 de março de 2018. Disponível

<http://www.stf.jus.br/portal/cms/verNoticiaDetalhe.asp?idConteudo=371164>. Acesso em 23 de junho de2018.

BUTLER, Judith. Problemas de gênero: feminismo e subversão da identidade. Editora Record, 2003.

CORREGEDORIA GERAL DA JUSTIÇA DO ESTADO DE GOIÁS. Provimento $\mathbf{n}^{\mathbf{0}} \mathbf{1 7}$, de 22 de maio de 2018. Dispõe sobre a averbação da alteração do prenome e do gênero nos assentos de nascimento e casamento de pessoas trans no Registro Civil de Pessoas Naturais. Publicação: quarta-feira, 23/05/2018. Disponível em: http://ibdfam.org.br/assets/img/upload/files/Provimento\%20n\%C2\%BA\%20172018_esse.pdf. Acesso em 23 de junho de 2018.

Rev. de Direitos Sociais, Seguridade e Previdência Social | e-ISSN: 2525-9865 | Porto Alegre | v. 4 | n. 2 | p. 1 - 16 | Jul/Dez. 
CRUZ, Rodrigo Chandohá da. A concessão de aposentadoria ao transexual equivalente ao sexo adequado. 1. ed. Curitiba: CRV, 2014

DE FREITAS, M. S; VITA, J. B. Distinção de Gênero para Fins de Aposentação e a Tutela Jurídica das Pessoas Transexuais.Novos Estudos Jurídicos,22(1), 2017, p. 288-323.

DE OLIVEIRA, João Felipe Zini Cavalcante et al. Lei de Identidade de Gênero: Uma AnáliseComparativa da Lei Argentina e o Pl 5002/2013 do Brasil. Libertas: Revista de PesquisaemDireito, v. 2, n. 1, 2016.

DE SÁ NETO, et al. Caminhando entre a (in) visibilidade: uma análise jurídica sobre o projeto de lei $\mathrm{n}^{\circ}$ 5. 012/2013-Lei de Identidade de Gênero.Revista Direito e Liberdade-Escola da Magistratura do Rio Grande do Norte 16, no. 1 (2014): 55-72.

EUROPE, TGEU-Transgender. World Health Organisation moves toendclassifyingtransidentitiesasmentalilness. Postedon 18, june, 2018, in "International Day ofAction for TransDepathologization, Depathologisation, Health e Depathologisation, Press, Health \&Depathologisation. Disponível em: https://tgeu.org/world-health-organisationmoves-to-end-classifying-trans-identities-as-mental-illness/. Acesso em 23 de junho de 2018.

JESUS, Jaqueline Gomes de, e ALVES, Hailey. Feminismo Transgênero e Movimentos de Mulheres Transgêneros in CRONOS - Revista do Programa de Pós-Graduação em Ciências da UFRN, vol. 11. Natal, 2010

JESUS, Jaqueline Gomes de. Pessoas transexuais como reconstrutoras de suas identidades: reflexões sobre o desafio do direito ao gênero. In Galinkin, Ana L. \& Santos, Karine B. (orgs.), Anais do Simpósio Gênero e Psicologia Social: diálogos interdisciplinares, 80-89, 2010.

OMS. Organização Mundial da Saúde. Disponível em: <http://www.who.int/healthtopics/international-classification-of-diseases >. Acesso em 23 de junho de 2018

SALIH, Sara. Judith Butler e a Teoria Queer/Sara Salih. Tradução e notas Guacira Lopes Louro. Belo Horizonte: Autêntica Editora, 2012.

SOUZA, Fábio Costa de. Transgeneridade e Sistema de Proteção Social no Brasil: O caso do Sistema Previdenciário Brasileiro, in "Informe de Previdência Social", outubro/2015, volume 27, número 10, Brasília - $\quad$ DF. Disponível em:<http://sa.previdencia.gov.br/site/2016/06/informe_2015.10.pdf > Acesso em 23 de junho de 2018.

TRIBUNAL DE JUSTIÇA DO RIO GRANDE DO SUL. Provimento n²1/2018 - CGJ Provimento RS. RCPN - Alteração do prenome e gênero de transgêneros. Acrescenta a Subseção I - DA AVERBAÇÃ̃O DA ALTERAÇÃO DO PRENOME E SEXO DE TRANSGÊNEROS -, na Seção IV, do Capítulo V, do Título II, e os artigos 114-A e parágrafos, 114-B e parágrafos, 114-C e parágrafo único, e 114-D a 114-F, na Consolidação Normativa Notarial e Registral - CNNR. Porto Alegre, 15 de maio de 2018. Disponível em: < http://colegioregistralrs.org.br:10091/imagens/provimento_152658542768.pdf> Acesso em 23 de junho de 2018.

Rev. de Direitos Sociais, Seguridade e Previdência Social | e-ISSN: 2525-9865 | Porto Alegre | v. 4 | n. 2 | p. 1 -16 | Jul/Dez. 